\title{
Cryogenic Pressure Control Modeling for Ellipsoidal Space Tanks in Reduced Gravity
}

\author{
Alfredo Lopez ${ }^{1}$, Gary D. Grayson ${ }^{2}$, and Frank O. Chandler ${ }^{3}$ \\ The Boeing Company, Huntington Beach, CA, 92647 \\ Leon J. Hastings ${ }^{4}$ \\ Alpha Technology, Inc., Huntsville, Alabama, 35812 \\ and \\ Ali Hedayat ${ }^{5}$ \\ NASA Marshall Space Flight Center, Huntsville, Alabama, 35812
}

\begin{abstract}
A computational fluid dynamics (CFD) model is developed to simulate pressure control of an ellipsoidal-shaped liquid hydrogen tank under external heating in low gravity. Pressure control is provided by an axial jet thermodynamic vent system (TVS) centered within the vessel that injects cooler liquid into the tank, mixing the contents and reducing tank pressure. The two-phase cryogenic tank model considers liquid hydrogen in its own vapor with liquid density varying with temperature only and a fully compressible ullage. The axisymmetric model is developed using a custom version of the commercially available FLOW-3D software and simulates low gravity extrapolations of engineering checkout tests performed at Marshall Space Flight Center in 1999 in support of the Solar Thermal Upper Stage Technology Demonstrator (STUSTD) program. Model results illustrate that stable low gravity liquid-gas interfaces are maintained during all phases of the pressure control cycle. Steady and relatively smooth ullage pressurization rates are predicted. This work advances current low gravity CFD modeling capabilities for cryogenic pressure control and aids the development a low cost CFD-based design process for space hardware.
\end{abstract}

\section{Nomenclature}

$d p / d t \quad=$ ullage pressure rise rate

$V_{\max } \quad=$ maximum velocity within the domain

\section{Introduction}

$\mathrm{N}$

ASA's space exploration program is considering high energy cryogenic propellants for the Earth departure, Lunar descent, and Lunar ascent stages. The advancement of cryogenic fluid management (CFM) technology is essential to the development of these upper stages. NASA is teaming with its industrial partners to progress development/technology that will broaden the experience base for the CFM community as a whole. Microgravity experiments and relevant data are highly expensive and limited. This issue has motivated the Marshall Space Flight Center (MSFC)/Boeing team to aggressively explore combinations of ground testing and analytical modeling to the greatest extent possible.

Cryogenic propellant computational fluid dynamics (CFD) tools offer low cost design solutions for the aerospace industry to model low-g fluid dynamic effects. During earlier space programs, such as the Apollo and Space

\footnotetext{
${ }^{1}$ Associate Engineer/Scientist, Propulsion \& Cryogenic Technologies, 5301 Bolsa, Ave/H017-D725, Member.

${ }^{2}$ Associate Technical Fellow, Propulsion \& Cryogenic Technologies, 5301 Bolsa Ave/ H017-D725, Senior Member.

${ }^{3}$ Director, Propulsion \& Cryogenic Technologies, 5301 Bolsa Ave/ H017-D725, Associate Fellow.

${ }^{4}$ CFM Technology Consultant, Propulsion Systems Dept. ER24/ATI, Associate Member.

${ }^{5}$ Aerospace Engineer, Cryogenic Fluid Management Technology Team, Propulsion Systems Dept. ER24, Senior Member.
} 
Shuttle, design activity related to how a specific tank would perform in zero g was based on estimates for the performance using simple models for the internal fluid components such as galleries and collectors. Qualification of these components could involve drop tower testing, parabolic aircraft flight testing or extensive ground testing in more severe g-level tank orientations than would be needed in actual flight. With the advent of these sophisticated CFD codes and the ability to model these complex internal propellant management geometries, high fidelity solutions and propellant tank operational verification can now be obtained by analysis at a fraction of the original cost needed for an elaborate test.

Propellant tank pressure control in reduced gravity is an enabling technology for implementing in-space cryogenic propulsion. Upper stage tank pressure control currently relies on propellant settling and venting as required, however, auxiliary systems for propellant settling incur weight penalties in the form of setting propellant and hardware. Complexity is also incorporated into the mission operations because venting/resettling of the propellant can become necessary at inopportune times such as when liquid propellant is situated at the vent port. The thermodynamic vent system (TVS) concept enables tank pressure control and venting without resettling.

A series of ground tests were conducted at MSFC for Boeing and SRS Technologies using the $2 \mathrm{~m}^{3}\left(71 \mathrm{ft}^{3}\right)$ Solar Upper Stage Technology Demonstrator (STUSTD) tank (Fig. 1) to demonstrate reduced gravity pressure control. Details of the STUSTD program and engineering tests are available in Ref. 4. This paper expands on previously published model results (Ref. 1) and presents the pressure control and active TVS performance data for the STUSTD tank in a reduced gravity environment.

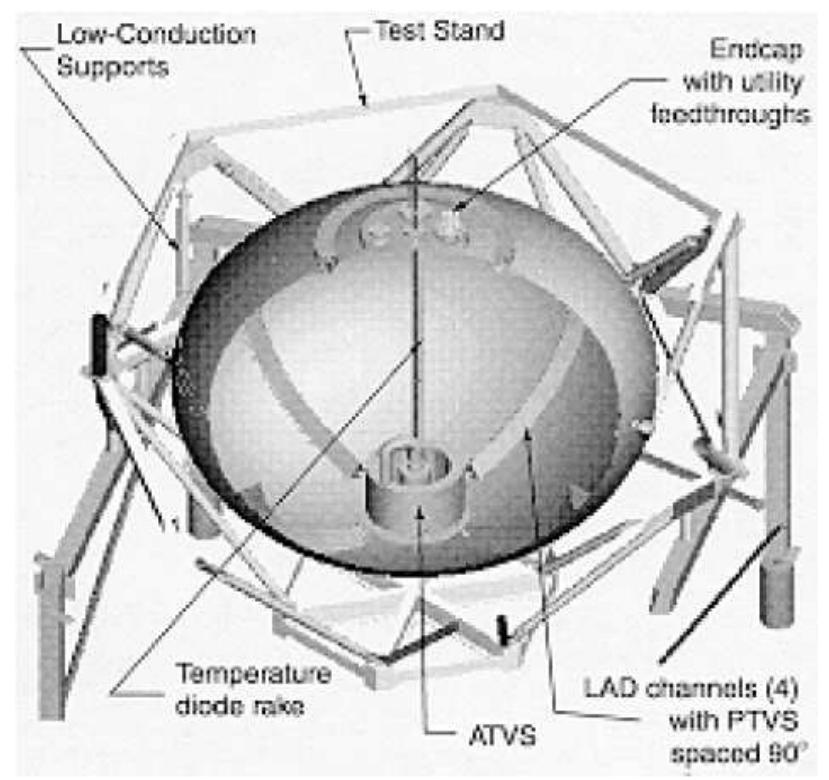

Figure 1. STUSTD Tank Configuration.

\section{Approach}

\section{A. FLOW-3D Software}

FLOW-3D is a general Navier-Stokes equation solver with an extensive history of cryogenic tank modeling in both reduced and normal gravity environments. FLOW-3D allows several options to be enabled based on what is important to the problem. The current two-phase cryogenic tank model is developed using a custom version of the commercially available FLOW-3D software. The customization enables the model to treat phase change effects at the liquid-gas interface. First order approximations for momentum and energy equations including the two equation $\mathrm{k}-\varepsilon$ and Renormalization-Group (RNG) turbulence models are enabled. The ullage region is treated as fully compressible and liquid density varies with temperature only. Modeling the heat transfer between liquid, gas and tank walls is included to capture thermal stratification within the fluids. For details of the formulations and assumptions within the FLOW-3D code see Ref. 6 . 


\section{B. Model Description}

The model uses a 3,250 cell axisymmetric mesh to simulate the $71 \mathrm{ft}^{3}$ ellipsoidal STUSTD tank (Fig. 2). The mesh is derived from a similar tank pressurization model (Ref. 2) The S-IVB mesh has previously been shown to be independent of grid size therefore the current STUSTD mesh is expected to provide a grid insensitive solution. The tank has a width of 5.78-ft. and a height of 4.08-ft. Liquid acquisition devices (LADs) are omitted from the model because the engineering checkout tests do not include LAD operation. The Active TVS (ATVS) is located in the center of the tank and is 1 - $\mathrm{ft}$. in diameter and 0.63 -ft. tall. The outlet of the axial jet is $0.14-\mathrm{ft}$. (1.7-in.) in diameter.

A series of dual capacity $(20 \mathrm{~W}$ and $40 \mathrm{~W})$ tank wall heaters are imbedded in the tank insulation. Due to the axisymmetric mesh, the STUSTD model incorporates these variable power tank heaters as solid obstacles adjacent to the bulk liquid. The actual tank heaters are approximately 6 inches wide by 26 inches long. Four of these tank heater strips are evenly distributed on the tank wall. The tank heat leak is distributed between the tank wall and the imbedded heater obstacles. When heaters are not used the incoming tank heat leak is evenly distributed along the tank walls including the surface of the inactive heaters.

The ATVS body is considered adiabatic thus contributing a negligible amount of heat to the liquid. The selfpressurization models are initially quiescent. The liquid is assumed saturated at a given tank pressure and allowed to heat up. Ullage stratification profiles are derived from available test data and applied on a case by case basis.

Table 1 lists the test cases considered in the present analysis. The focus is on tank self-pressurization and ATVS performance in reduced gravity environments.

By correlating the two-phase cryogenic model to normal gravity test data and using verified low-gravity slosh modeling techniques for spacecraft and launch vehicles, cryogenic tank pressure control in reduced gravity environments can be simulated. Here, each of the normal gravity cases previously discussed (Ref. 1) is run in a 1E-5-g acceleration environment with identical fills and heat conditions as the normal gravity cases. The low gravity model uses an identical computational mesh as the normal gravity models. Predicted ullage pressure, ullage temperature and liquid temperature histories are presented. Temperature contour and velocity plots are included to track liquid/gas interaction and illustrate how the surface tension dominated fluid regions react to external heating in reduced acceleration environments.

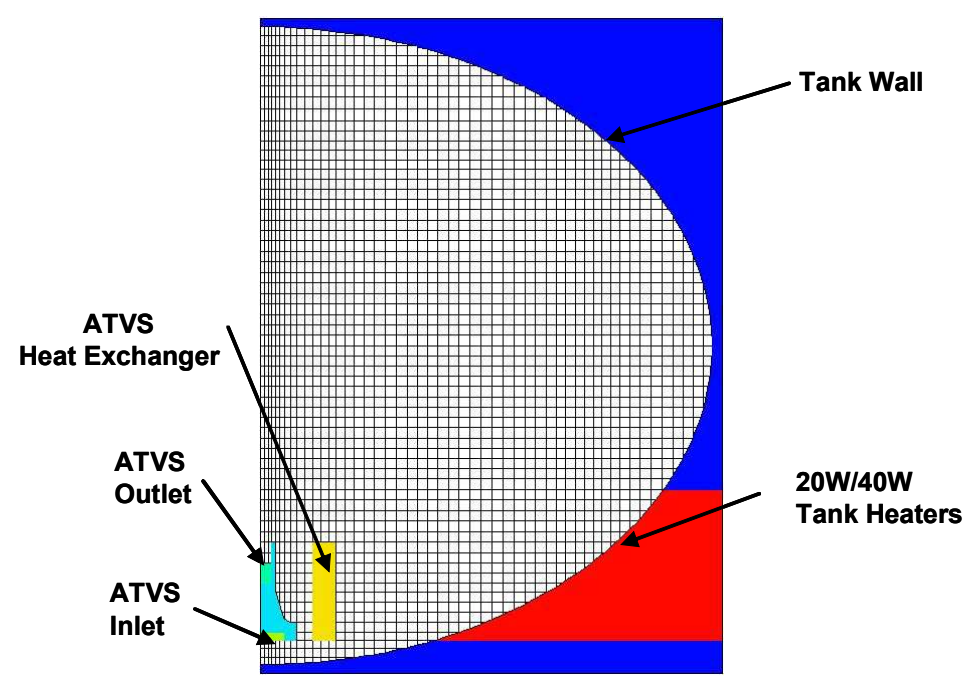

Figure 2. STUSTD Model Mesh and Tank Geometry.

\begin{tabular}{|c|c|c|c|c|}
\hline Test Case & Test Fluid & Heat Leak Rate & Fill Level & $\begin{array}{c}\text { Mixer Type \& Flow } \\
\text { Rate }\end{array}$ \\
\hline 1 & LH2 & $25.7 \mathrm{~W}$ & $87 \%$ & none \\
\hline 2 & LH2 & $25.7 \mathrm{~W}$ & $44 \%$ & none \\
\hline 3 & LH2 & $6.7 \mathrm{~W}$ & $90 \%$ & axial jet $/ 27 \mathrm{gpm}$ \\
\hline
\end{tabular}

Table 1. STUSTD Reduced Gravity Test Cases. 


\section{Results and Discussion}

When in reduced gravity, the surface tension forces in the STUSTD tank are significant compared to all other forces. As expected in a low-gravity environment with a tank of this size, the meniscus at the tank wall begins to grow as surface tension forces pull the liquid towards a curved shape. The ullage will eventually form a nearly spherical ullage bubble within the tank to minimize surface energy. Accordingly in Cases 1 and 3 , the initial bubble shape is specified as precisely spherical and then the model simulates the equilibrium shape from that initial bubble. For the lower fill fraction simulations (Cases 2) a flat initial free surface is specified and the code is allowed to develop that initial shape into the equilibrium shape for the fluid, geometry, and tank considered.

\section{A. Self-Pressurization}

In Case 1, self-pressurization of the STUSTD LH2 tank is simulated using an $87 \%$ fill level with $25.7 \mathrm{~W}$ heat leaks. Heat is distributed between tank walls $(5.7 \mathrm{~W})$ and tank heaters operating at $20 \mathrm{~W}$. Figure 3 shows that an average tank pressurization rate of $0.72 \mathrm{psi} / \mathrm{hr}$ is predicted for Case 1 and remains relatively smooth throughout the 10,000-sec simulation. Ullage temperatures (Fig. 4) and liquid temperatures (Fig. 5) are measured at 44 inches and 25 inches from the bottom of the tank respectively. Model results for ullage and liquid temperature for Case 1 experience a small $\left(1^{\circ} \mathrm{R}\right)$ increase in magnitude during self-pressurization. Figures $6 \mathrm{a}$ and $6 \mathrm{~b}$ illustrate that a stable liquid/gas interface is maintained throughout the self-pressurization phase. Small localized bubble interface disturbances, with velocities on the order of $0.004 \mathrm{ft} / \mathrm{s}$ to $0.02 \mathrm{ft} / \mathrm{s}$, are noted but they do not affect the ullage bubble significantly. In a reduced gravity environment, the energy exchange between the bulk liquid and tank heater has a significant effect on the total tank thermal distribution. In Figure 6a, the influence the tank heaters have on the surrounding fluid can be observed. In the absence of strong natural convection currents, warm spots begin to form throughout the tank. More noticeably the center of the ullage bubble is generally warmer (typically $1.5^{\circ} \mathrm{R}$ warmer than surround liquid) than other areas of the tank. The ullage bubble begins to warm the surrounding liquid as well. This is illustrated throughout the temperature contour plots where slightly warmer liquid surrounds the ullage bubble.

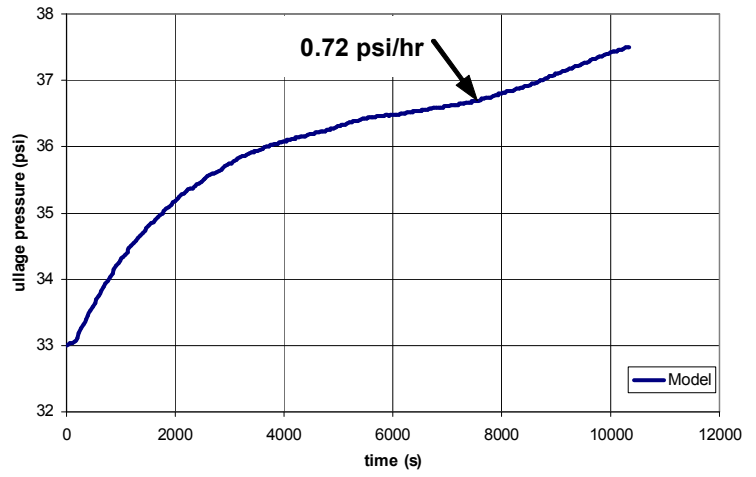

Figure 3. Case 1 Ullage Pressure History.

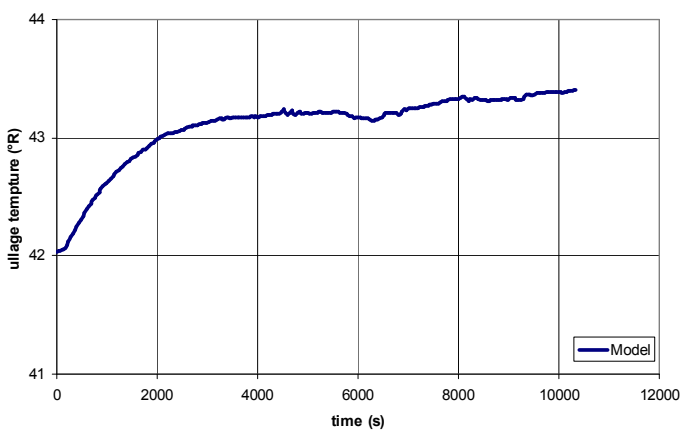

Figure 4. Case 1 Ullage Temperature History.

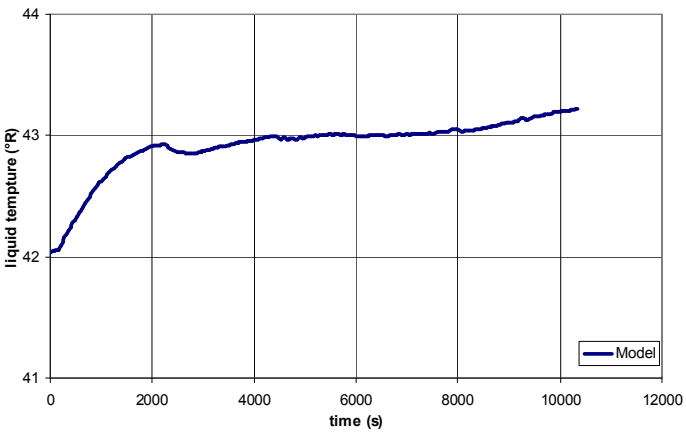

Figure 5. Case 1 Liquid Temperature History (25-in.). 


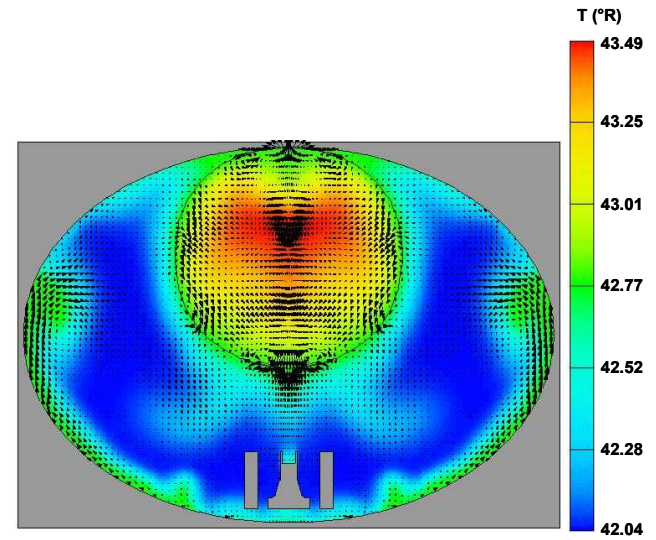

a.) $\mathrm{t}=4680 \mathrm{~s}, \mathrm{~V}_{\max }=0.00159 \mathrm{ft} / \mathrm{s}$

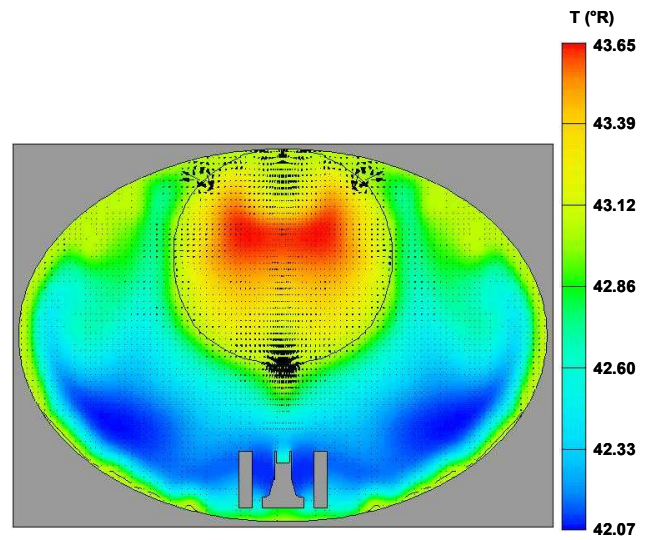

b.) $\mathrm{t}=10,320 \mathrm{~s}, \mathrm{~V}_{\max }=0.00832 \mathrm{ft} / \mathrm{s}$

Figure 6. Case 1 Temperature and Velocity Field Plots.

In Case $2(25.7 \mathrm{~W}, 44 \%$ fill $)$ the tank heaters are activated. A steady self-pressurization rate of $1.44 \mathrm{psi} / \mathrm{hr}$ is predicted. Figure 10b illustrates pockets of warm gas at the liquid-heater interface slowly traveling along the sidewall. The transient motion within the tank cause small scale oscillations in ullage temperatures on the order of less than $2^{\circ} \mathrm{R}$. Liquid temperature (Fig. 9) is recorded at 15 inches from the bottom of the tank and experiences little change during self-pressurization. At a $44 \%$ fill, the liquid-gas interface becomes notably curved as velocity and temperature fields with in the tank develop. Surface tension forces draw liquid hydrogen along the walls. The liquid has a higher heat capacity than the ullage and therefore when the liquid intercepts incident tank wall heat leak the overall heat leak into the ullage region is reduced. This leads to slightly lower ullage pressurization rates than in normal gravity for the STUSTD/SRS configurations studied (Ref. 1).

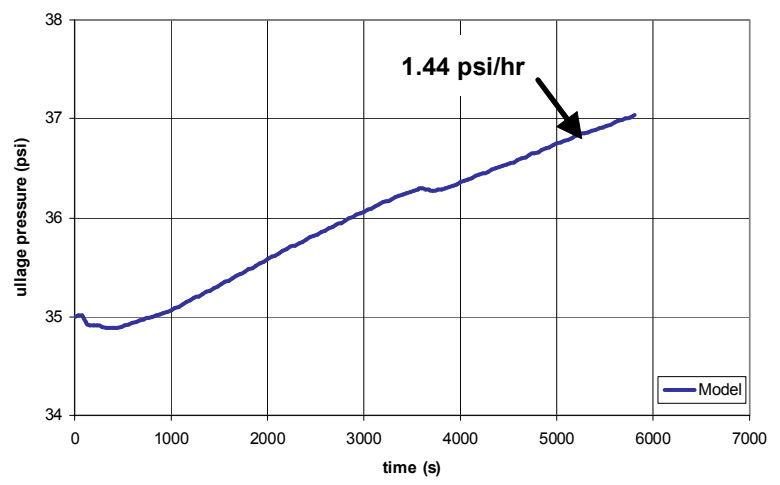

Figure 7. Case 2 Ullage Pressure History.

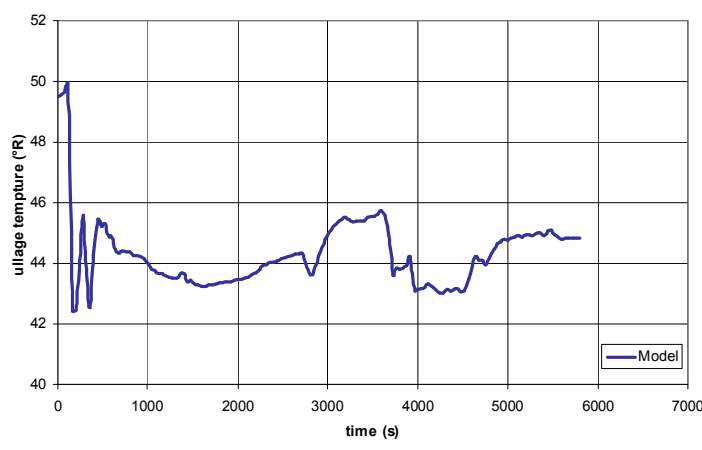

Figure 8. Case 2 Ullage Temperature History.

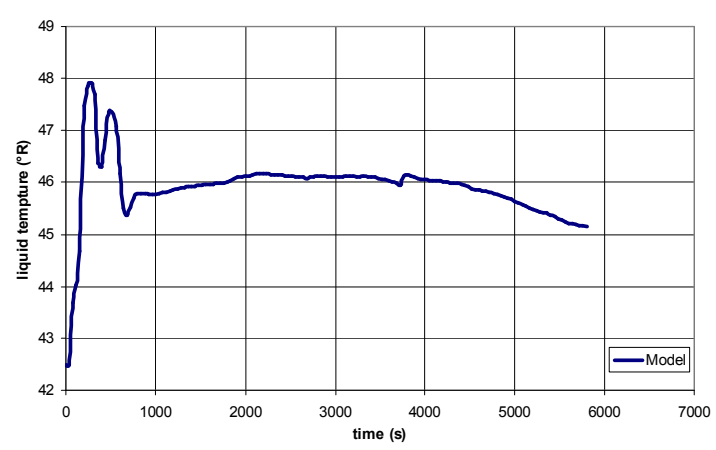

Figure 9. Case 2 Liquid Temperature History (15-in.). 


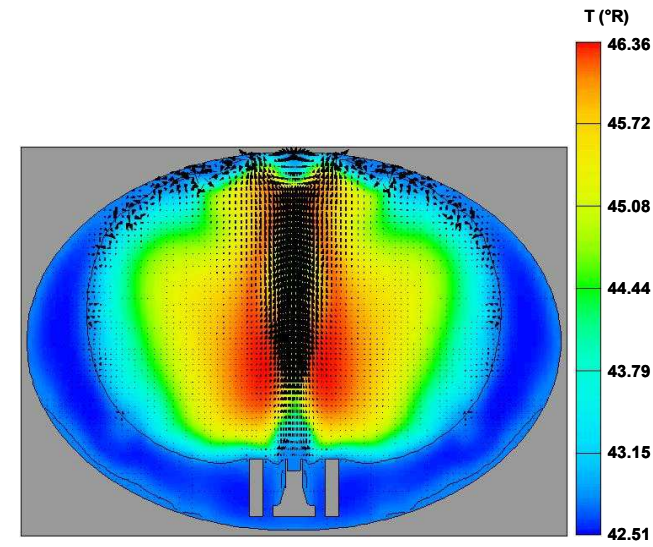

a.) $t=3600 \mathrm{~s}, V_{\max }=0.0102 \mathrm{ft} / \mathrm{s}$

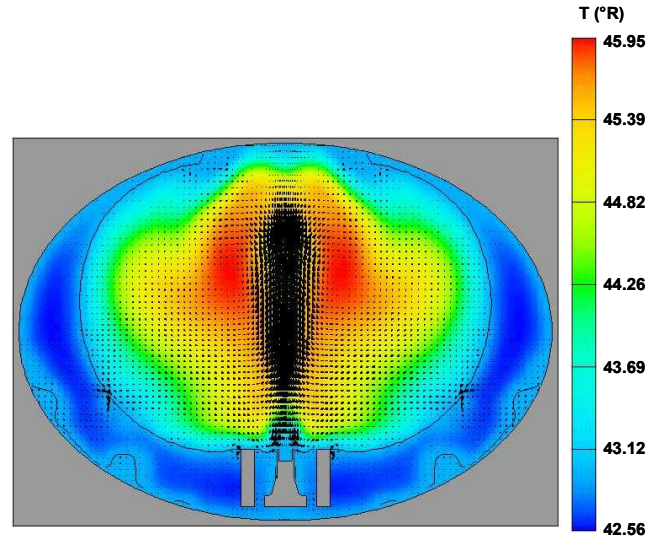

b.) $t=5680 \mathrm{~s}, V_{\max }=0.00528 \mathrm{ft} / \mathrm{s}$

Figure 10. Case 2 Temperature and Velocity Field Plots.

\section{B. Active TVS Activation}

Thermodynamic vent system (TVS) operation in low gravity is simulated by Case $3(6.7 \mathrm{~W}, 90 \%$ fill, 27 GPM); see Figs. 11 to 14 . Total tank heat leak is $6.7 \mathrm{~W}$ and is evenly distributed along the side walls. The tank heaters in this case are deactivated. The LH2 is initially saturated at $16.5 \mathrm{psi}\left(37.2^{\circ} \mathrm{R}\right)$ with an initial spherical $10 \%$ ullage bubble. The model predicts a steady ullage pressure rise rate of $0.29 \mathrm{psi} / \mathrm{hr}$. This predicted rate is equivalent to normal gravity predictions (Ref. 1). The small ullage bubble shows a negligible response to the reduced gravity environment. At 5,160 seconds (Fig. 14a), the ullage bubble situates itself toward the forward dome of the elliptical STUSTD tank. A small portion of the ullage is exposed to the $6.7 \mathrm{~W}$ entering through the tank walls. Therefore the slightly higher than expected

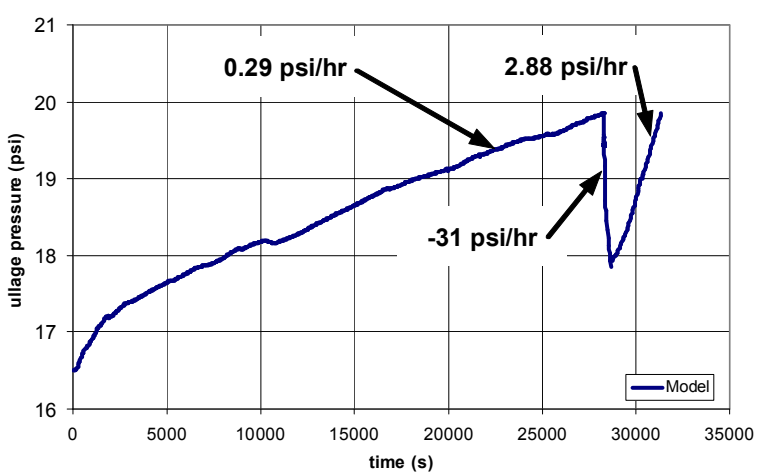

Figure 11. Case 3 Ullage Pressure History.

ullage pressurization rate may be due to the ullage receiving similar amounts of heat to the normal gravity case despite liquid covering the tank walls. Temperatures of the ullage gas (44 inches from tank bottom) and liquid temperature (30 inches from tank bottom) are shown in Figures 12 and 13 and illustrate negligible changes during self-pressurization. At 28,320 seconds (Fig. 14b) tank pressure reaches about $20 \mathrm{psi}$ and the active TVS is activated. Sub-cooled LH2 at $36.8^{\circ} \mathrm{R}$ is jetted axially into the tank at approximately $3.82 \mathrm{ft} / \mathrm{s}$ while warm LH2 is drawn from the bottom of the tank. Figure 14c illustrates good mixing by the axial jet. In a reduced gravity environment, the jet achieves complete ullage penetration and impacts the opposite side of the elliptical tank. This generates a small ullage bubble toward the center of the tank as the liquid flows along the tank walls. The temperature field within the tank is effectively uniform at $37.8^{\circ} \mathrm{R}$. At 320 seconds (Fig. 14d) following active TVS start up, tank pressure reaches $18 \mathrm{psi}$. The model predicts an ullage pressure drop of $31 \mathrm{psi} / \mathrm{hr}$ higher than normal gravity results. The heaters are activated to $40 \mathrm{~W}$ and the tank begins to repressurization. Approximately 680 seconds after the TVS is deactivated (Fig. 14e) residual motion on the order of $0.551 \mathrm{ft} / \mathrm{s}$ is noted. The small ullage bubble moves toward the center of the tank and returns to a spherical shape toward the forward dome of the tank. With the heaters activated, thermal boundary layers transport pockets of warm gas at the heat interface along the tank walls (Fig. 14f). During repressurization, an expectedly higher average ullage repressurization rate of $2.88 \mathrm{psi} / \mathrm{hr}$ and an appreciable increase in ullage and liquid temperatures are predicted. 


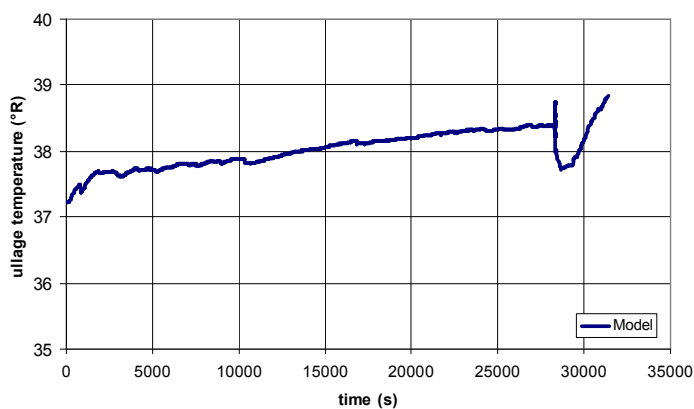

Figure 12. Case 3 Ullage Temperature History.

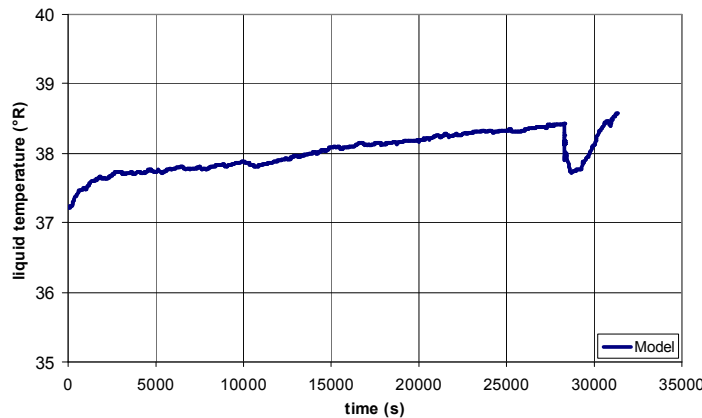

Figure 13. Case 3 Liquid Temperature History (30-in.). 

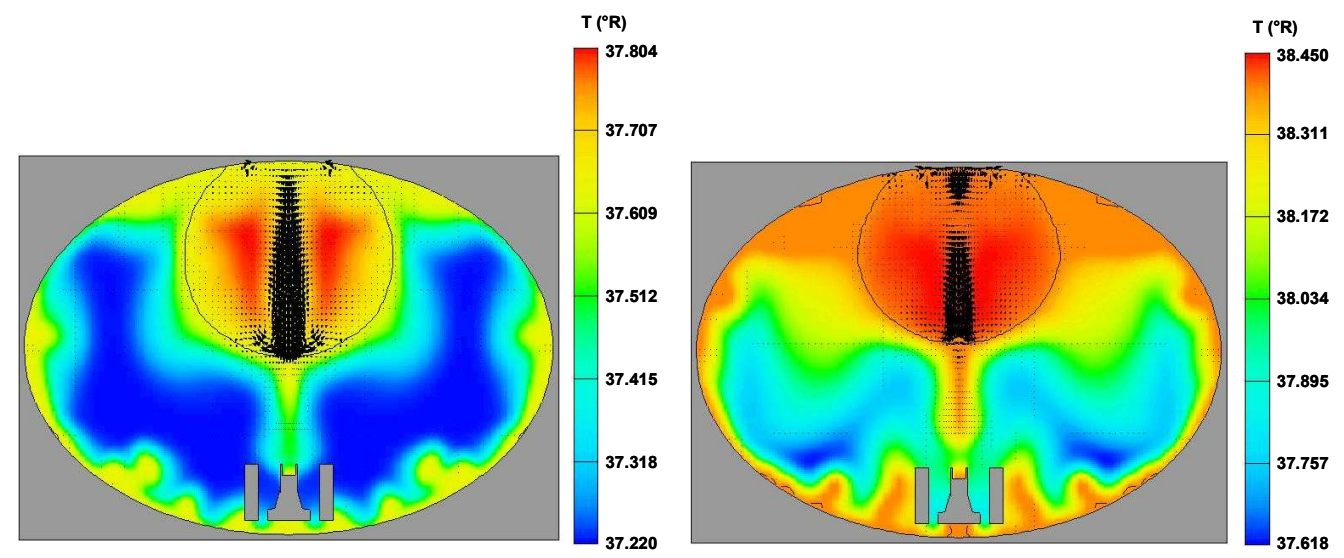

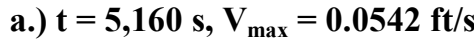

b.) $\mathbf{t}=28,320 \mathrm{~s}, \mathrm{~V}_{\max }=0.0465 \mathrm{ft} / \mathrm{s}$
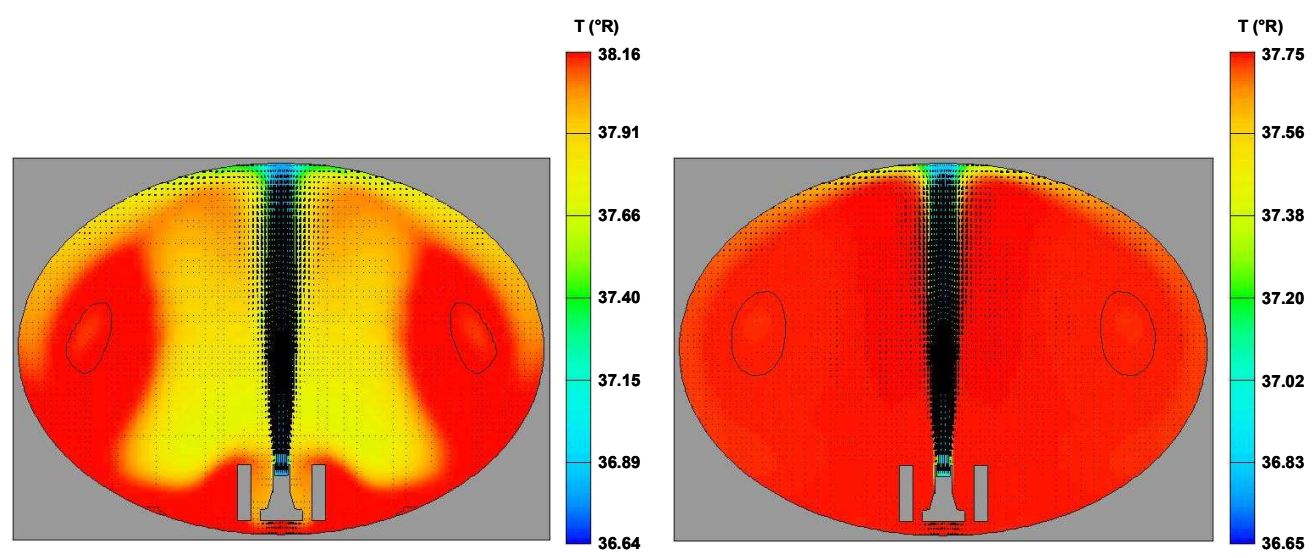

c.) $t=28,320 \mathrm{~s}, \mathrm{~V}_{\max }=3.82 \mathrm{ft} / \mathrm{s}$

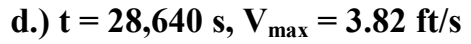

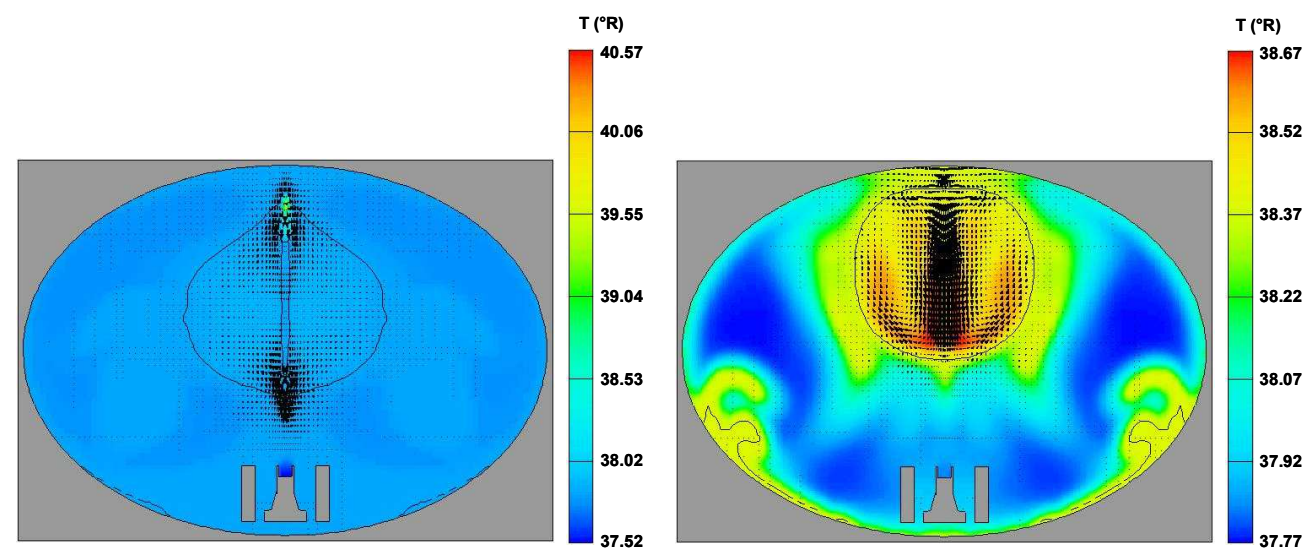

e.) $t=29,320 \mathrm{~s}, \mathrm{~V}_{\max }=0.551 \mathrm{ft} / \mathrm{s}$

f.) $t=31,480 \mathrm{~s}, V_{\max }=0.0678 \mathrm{ft} / \mathrm{s}$

Figure 14. Case 3 Temperature and Velocity Field Plots. 
A summary of average pressurization rates of the elliptical STUSTD/SRS tank in reduced gravity is presented in Table 2. This set of data illustrates the effect on reduced gravity tank self-pressurization by varying heat leak and fill fraction and how they compare to normal gravity results. Test cases with higher heating conditions demonstrate higher pressurization rates in both operating environments. In addition, high fill fraction (small ullage) test cases (e.g., Cases 1 and 3) exhibit an average pressurization rate that is lower than the low fill fraction (large bubble) test cases (e.g., Cases 2) for the heat leak boundary conditions assumed. Cases 1 and 2 also show how reduced gravity self-pressurization rates are lower in magnitude than in normal gravity. Surface tension forces drive liquid along the sidewalls and intercept more of the incident heat leak subsequently reducing the pressurization rate.

\begin{tabular}{|c|c|c|c|c|}
\hline Test Case & $\begin{array}{c}\text { Heat Leak } \\
\text { Rate }\end{array}$ & Fill Level & $\begin{array}{c}\text { Normal gravity } \\
\text { dp/dt (psi/hr) }\end{array}$ & $\begin{array}{c}\text { Reduced gravity } \\
\text { dp/dt (psi/hr) }\end{array}$ \\
\hline 1 & $25.7 \mathrm{~W}$ & $87 \%$ & 1.0 & 0.7 \\
\hline 2 & $25.7 \mathrm{~W}$ & $44 \%$ & 1.45 & 1.44 \\
\hline 3 & $6.7 \mathrm{~W}$ & $90 \%$ & 0.29 & 0.29 \\
\hline
\end{tabular}

Table 2. STUSTD Model Results Summary.

\section{Conclusion}

For reduced gravity environments, pressure control is again demonstrated successfully where stable low gravity liquid-gas interfaces are maintained during all phases of the pressure control cycle. Steady and smooth ullage pressurization rates are predicted. The work presented advances current low gravity CFD modeling capabilities for cryogenic pressure control and helps the development a low cost CFD-based design process for space hardware.

\section{Acknowledgments}

This work was supported by the NASA Marshall Space Flight Center under the Pressure Control Data Correlation contract NNM05AB18C.

\section{References}

${ }^{1}$ Lopez, A. and Grayson, G.D., "Cryogenic Pressure Control Modeling for Ellipsoidal Space Tanks," AIAA Paper 20075552, July 2007.

${ }^{2}$ Grayson, G.D. and Lopez, A., "Cryogenic Tank Modeling for the Saturn AS-203 Experiment," AIAA Paper 2006-5258, July 2006.

${ }^{3}$ Olsen, A.D., Cady, E.C., and Jenkins, D.S., "Solar Thermal Upper Stage Cryogen System Engineering Checkout Test," AIAA Paper 99-2604, June 1999.

${ }^{4}$ Lin, C.S., Van Dresar, N.T., and Hasan, M.M., "A Pressure Control Analysis of Cryogenic Storage Systems,” AIAA Paper 91-2405, June 1991.

${ }^{5}$ Winters, B.A., "Analysis of the Solar Thermal Upper Stage Technology Demonstrator liquid acquisition device with integrated thermodynamic vent system," AIAA Paper 96-2745, July 1996.

${ }^{6}$ FLOW-3D User's Manual, version 9.0, Flow Science, Inc., Santa Fe, NM 2005. 